\title{
Molecular Dynamics Simulation of Adsorption Behavior of Schiff base Gemini Surfactants on Zn (1 110$)$ Surface
}

\author{
Haiying Li ${ }^{l}$, Zheng Liu ${ }^{1, *}$, Hao Wang ${ }^{1}$, Guo-Cheng Han ${ }^{2, *}$, Yong Zhao, Si-wei Xie ${ }^{l}$, Shufen Zhang ${ }^{l}$, \\ Zhencheng Chen ${ }^{2}$, Shuang $\mathrm{Li}^{2}$ \\ ${ }^{1}$ Chemistry and Biological Engineering, Guilin University of Technology, Guilin, 541004, P.R. China \\ ${ }^{2}$ School of Life and Environmental Sciences, Guilin University of Electronic Technology, Guilin \\ 541004, P.R. China \\ *E-mail: lisa4.6@163.com, hangc1981@163.com
}

doi: $10.20964 / 2017.07 .29$

Received: 12 March 2017 / Accepted: 27 April 2017 / Published: 12 June 2017

\begin{abstract}
Molecular dynamics simulation method was selected to investigate the adsorption behavior of three quaternary ammonium Schiff base Gemini surfactants on Zn (lllll 10$)$ surface, including 4,4'-(hydrazine1,2-diylidenebis-(methanylylidene))bis-(N-decyl-N,N-dimethylbenzenaminium)bromide(D1),4,4'(hydrazine-1,2-diylidenebis(methanylylidene))bis(N-dodecyl-N,N-dimethylbenzenaminium) bromide (D2), and 4,4'-(hydrazine-1,2-diylidenebis(methanylylidene))bis(N-myristyl-N,N-dimethylbenzenaminium)bromide(D3). The electrochemical impedance spectroscopy (EIS) and scanning electron microscope (SEM) showed that D3 had better corrosion inhibition performance for the zinc electrode and more excellent inhibitory effect on dendrite, deformation and passivation of zinc. The molecular dynamics simulation results indicated that the order of adsorption energy of three Schiff base Gemini surfactants was D3 $>$ D2 $>$ D1, the adsorption rate followed the order of D3 $>$ D2 $>$ D1. The adsorption energy was greater and the adsorption rate was faster, D3 had the best effect on corrosion inhibition, inhibiting dendrite and deformation.
\end{abstract}

Keywords: Schiff base Gemini surfactants; molecular dynamics simulation; adsorption behavior; corrosion inhibition

\section{$\underline{\text { FULL TEXT }}$}

(C) 2017 The Authors. Published by ESG (www.electrochemsci.org). This article is an open access article distributed under the terms and conditions of the Creative Commons Attribution license (http://creativecommons.org/licenses/by/4.0/). 